\title{
Who is Afraid of Asian FX Interventions? Large Lessons for Europe from a Three-asset- portfolio Model
}

\author{
Sebastian Dullien*
}

The paper develops a three-asset-portfolio model to analyse consequences of foreign exchange market operations by Asian central banks on the exchange rates between euro, dollar and an Asian currency. It is found that - contrary to public belief - the purchase of dollar assets by Asian central banks strengthens the dollar against both the euro and the Asian currency. A diversification of Asian central bank reserves from dollar into euro would weaken the dollar against both other currencies. Thus, such a diversification would be incompatible with Asian currency pegs. However, it is shown that Asian central banks could alter their relative porffolio composition while keeping the peg intact if they shifted from intervening against the dollar into intervening against the euro.

JEL classification: $F_{3} I$

Keywords: foreign exchange interventions, exchange rates, revived BrettonWoods-System

\section{Introduction}

One of the hottest topics in international finance has lately been the pegging of Asian currencies to the U.S. dollar and the huge foreign exchange interventions necessary to keep this peg intact. According to Roubini and Setser (2005), at the peak of interventions in 2003, Asian central banks financed roughly $90 \%$ of the United States current account deficit in an attempt to limit appreciations of their own currency against the U.S. dollar. According

* FHTW Berlin, Germany

Correspondence Address:

Prof. Sebastian Dullien, FHTW Berlin, University of Applied Sciences, Department 3 - Economics I, Treskowallee 8, го3ıз Berlin, Germany, e-mail: dullien@web.de

Received 02 October 2007, accepted 23 June 2008

C) INTERVENTION 5 (2), 2008, 387-405 
to the numbers from the Chinese central bank, China alone bought $\$ 2$ oobn roughly in 2004, while Japan bought \$r6obn. The monetary authorities of South Korea and Taiwan have also been among the biggest buyers of dollar assets. While Japan has ended it's interventions in March 2004, the People's Bank of China as well as other central banks in developing Asia have continued to intervene heavily in the foreign exchange market until the time of writing of this paper.

In a series of influential papers, Dooley, Folkerts-Landau, and Garber (2003) have argued that the intervention policies by the Asian countries constitute a new Bretton Woods system. In the original Bretton Woods system, European and Asian countries had tied their currencies to the dollar. By thus safeguarding their competitiveness against the U.S., European countries and Japan managed to stimulate investment in export industries and integrate quickly into world markets. According to Dooley et al. 2003, this system is now revived by China, Korea and other emerging Asian countries. As the benefits from stable, undervalued exchange rates at the moment exceed the costs of financing the U.S. current account by reserve accumulation, they continue to buy U.S. assets to keep their currencies cheap.

Other authors such as Roubini and Setser (2005) or Eichengreen (2004) have speculated how long the revived Bretton Woods system can be sustainable. As each central bank by itself might not be willing to pile up dollar assets endlessly as they might lose value should the peg be abandoned anytime in the future, they have argued that the set-up is inherently unstable. According to them, an end of the revived Bretton Woods system is therefore imminent.

Europe has not participated in the informal Bretton Woods 2 system. It has neither run a large current account deficit which has been financed by Asia, nor has it engaged itself in large foreign exchange interventions to keep the euro cheap against the dollar. Nevertheless, Asian currency interventions have increasingly become a pressing topic among European policy makers. Journalists and politicians have repeatedly made Asian dollar purchases responsible for the appreciation of the euro against the dollar, claiming that the euro has to bear more of the necessary adjustment of the U.S. dollar as adjustment of the dollar against Asian currencies has been hindered by the pegs. ${ }^{I}$ On $\mathrm{G}_{7}$ meetings, calls on Asian governments to allow more exchange rate flexibility have almost become a standard element of the communiques.

Moreover, foreign exchange markets have lately reacted very strongly on rumours of a imminent shift in Asian exchange rate policies. When on February 22, 2005, a Korean central bank official was reported to have said that, "as foreign exchange reserves increase«, the Bank of Korea would "diversify the currencies in which it invests", the dollar lost almost two cents against the euro in a matter of hours. ${ }^{2}$ Only after Asian central banks had loudly denied any plans to sell dollars, the greenback stabilized again. With this market re-

I See for example the Economist's special section on the world economy in the edition September $20,2003$.

2 Financial Times, February 23, 2005 
action, the question of the Asian currency regime has clearly become an issue for Europe as well, as the euro has already been quite strong in historical terms and a further appreciation might hurt European exporters. In October 2007, when the euro reached a new record high against the dollar, the president of the ECB, Jean-Claude Trichet, the head of the euro-group of European finance ministers, Jean-Claude Juncker and EU commissioner Joaquin Almunia publicly declared that they would "go to China to talk about exchange rates ${ }^{3}$ with the government in Beijing.

However, there is very little literature yet on the effects of the revived Bretton Woods system on the exchange rates of countries not participating neither in the "center " nor in the "periphery«. ${ }^{4}$ While Blanchard, Giavazzi and Sa 2005 have speculated that an end of Asian currency interventions would weaken the dollar against the euro, they have yet to present a formal model. The situation is similar for the diversification issue. While Roubini and Setser (2005) have argued that the revived Bretton Woods system might unravel soon, and Dooley, Folkerts-Landau, and Garber (2004) have argued that a portfolio shift in Asian currency reserves would threaten Asian pegs and let the euro appreciate, they have not yet provided a formal analysis of the consequences of a shift of Asian currency reserves into euro.

This paper tries to close these gaps. It presents for the first time an analytical framework to analyse the questions raised from a European perspective both graphically and mathematically. The model used here is a simple three-asset-portfolio (euro, dollar and yen assets) model based on Branson (1979) and Branson and Henderson (1985), leaving most of the assumptions of the original model intact. By including assets denominated in three different currencies instead of domestic money, domestic bonds and foreign assets as in the original model, it will be possible to draw conclusions on the short-run consequences of central banks' behaviour not only on the exchange rate between the periphery and the center, but also on countries such as Europe who have not been intervening in foreign exchange markets. The graphical representation should help to apply the model in a very simple way to a number of the questions raised above and should make the model also suitable for classroom discussion.

The results thus derived are quite interesting: First, contrary to what has been stated by politicians and journalists often, Asian purchases of U.S. dollar assets strengthen the greenback against the euro. So, should Asian central banks stop buying dollars, the dollar would plunge against the euro. Second, the direct diversification of Asian central bank portfolios (that is an outright sale of dollars and a purchase of euros) leads to a depreciation of the dollar both against the euro and the Asian currencies. Consequently, a direct diversification is incompatible with the aim of the Asian central banks to keep their exchange rates fixed against the dollar. Third, however, by buying euro and selling their own currency, Asian central banks can both keep the peg against the dollar intact and diversify their

4 Dooley et al. (2004) call countries which have pegged their currency to the dollar and finance the U.S. current account deficit by foreign exchange interventions "periphery" while they call the U.S. "center«. 
portfolios (by changing the relative weights of dollar and euro assets). Consequently, such a policy can be expected before Asian countries let their currencies float.

This paper is organised as follows: Section 2 sets up the basic model and deduces multipliers for changes in the supply of the three assets types on the exchange rates vis-à-vis the euro. Section 3 then examines how the U.S. current account deficit and the Asian central banks' purchase of dollars influences the exchange rates. Section 4examines what a diversification of Asian central bank portfolios would do to the bilateral exchange rates and analyses in how far a peg can be sustained while central banks reduce the riskiness of their portfolios. Section 5 concludes.

\section{The Model: Basic Setup}

The model used in this paper is based on a portfolio model following Branson (1979) and Branson and Henderson (1985). Instead of Branson's original formulation of bonds, money and foreign assets as three possible asset classes, this paper's model includes three kinds of interest-bearing assets, each denominated in a different currency: assets in U.S.-dollars, assets in euro and assets in yen (alternatively, the reader can think of all variables denoted with $Y$ as Chinese Yuan assets). Official foreign exchange interventions affect exchange rates via the portfolio channel, one of the standard channels in the theory of FX interventions. ${ }^{6}$ In this paper, only short run consequences of the foreign exchange interventions are covered in order to keep the argument concise. Long run consequences as the change in foreign trade or real output in the economies concerned are neglected. ${ }^{7}$

\section{I The Equations}

The model is structured as follows: $S^{U S}$ denotes the supply of U.S. assets, $S^{Y}$ the supply of Yen-denominated assets, and $S^{E U}$ the supply of assets denominated in euro. $A^{x}$ denotes the portfolio demand of each asset class, which is assumed to have a few plausible properties: The demand for each asset is a positive function of that asset's yield $i^{x}$ and a negative function of the other assets' yields. Moreover, the demand for each asset is positively sloped in aggregate wealth $W$. It is further assumed that the supply of assets in all three currencies is positive. $^{8}$

5 For a straightforward exposition, see Gärtner (1997: I45ff) or Gandolfo (2002).

6 See e.g. Dominguez and Frankel (1993) or Sarno and Taylor (200I).

$7 \quad$ For an analysis of medium- and long run current account adjustment - albeit only in a two-asset world - see Blanchard et al. (2005).

8 Note that in line with standard portfolio models, the assets are only mperfect substitutes and hence have different yields. See i.e. Gandolfo (2002: 233). 
Equations (I) to (3) represent the equilibria in the three asset markets with $W$ denoting total wealth of the private sector measured in euro. ${ }^{9}$ Wealth is the sum of the euro value of assets in all three currencies (4). $e^{U S}$ denotes the euro/dollar exchange rate (measured as euro per dollar), $e^{Y}$ the euro/yen exchange rate (measured as euro per yen). Thus a fall in $e^{U S}$ represents a depreciation of the dollar against the euro, a fall in $e^{Y}$ a depreciation of the yen against the euro. For simplicity, yields on all three assets are assumed to be constant and determined by factors exogenous to the model such as national monetary policies and capital productivity, while the expectation of exchange rate changes is independent of the actual exchange rate. ${ }^{10}$ As the paper is about the short term impact of currency market interventions on exchange rates, in the tradition of Branson's 1979 and Branson and Henderson's 1985 short-run analysis, only the partial equilibrium $\mathrm{n}$ the asset market is regarded:

$$
\begin{aligned}
& A^{U S}\left(\begin{array}{c}
i^{U S}, i^{Y}, i^{E U}, W \\
+-\quad+
\end{array}\right)=e^{U S} S^{U S} \\
& A^{Y}\left(\begin{array}{c}
i^{U S}, i^{Y}, i^{E U}, W \\
-+-+
\end{array}\right)=e^{Y} S^{Y} \\
& A^{E U}\left(\begin{array}{c}
i^{U S}, i^{Y}, i^{E U}, W \\
--++
\end{array}\right)=S^{E U} \\
& W=e^{U S} S^{U S}+e^{Y} S^{Y}+S^{E U}
\end{aligned}
$$

From $e^{U S}$ and $e^{Y}$, we can derive a yen/dollar exchange rate (measured as yen per dollar) $e^{\text {cross: }}$

$$
e^{\text {cross }}=\frac{e^{U S}}{e^{Y}}
$$

\subsection{Analytical Solution}

The system (I) to (4) can be solved quite easily. Substituting (4) into (I) to (3) and totally differentiating yields:

$$
\begin{array}{r}
A_{W}^{U S}\left(e^{U S} d S^{U S}+e^{Y} d S^{Y}+d S^{U S}+S^{U S} d e^{U S}+S^{Y} d e^{Y}\right)-e^{U S} d S^{U S}-S^{U S} d e^{U S}=0 \\
A_{W}^{Y}\left(e^{U S} d S^{U S}+e^{Y} d S^{Y}+d S^{U S}+S^{U S} d e^{U S}+S^{Y} d e^{Y}\right)-e^{Y} d S^{Y}-S^{Y} d e^{Y}=0 \\
A_{W}^{E U}\left(e^{U S} d S^{U S}+e^{Y} d S^{Y}+d S^{U S}+S^{U S} d e^{U S}+S^{Y} d e^{Y}\right)-d S^{E U}=0
\end{array}
$$

9 As in other portfolio models, it has no relevance for the results whether wealth is measured in euro or in any of the other currencies.

IO The assumption of the expectation of the future exchange rate being ndependent of the actual exchange rate is also an assumption standard to portfolio models Gandolfo (2002) pecial case of this is the assumption of static exchange rate expectations. 
with subscripts denoting partial derivatives. Writing as a matrix and using Cramer's rule ${ }^{\mathrm{II}}$ yields the reaction of $e^{U S}$ and $e^{Y}$ when the supply of assets in any of the three currencies changes:

$$
\begin{aligned}
& d e^{U S}=-\frac{e^{U S}}{S^{U S}} d S^{U S}+\frac{A_{W}^{U S}}{A_{W}^{E U} S^{U S}} d S^{E U} \\
& d e^{Y}=-\frac{e^{Y}}{S^{Y}} d S^{Y}+\frac{A_{W}^{Y}}{A_{W}^{E U} S^{Y}} d S^{E U}
\end{aligned}
$$

For the cross exchange rate, we get from (5):

$$
d e^{\text {cross }}=\frac{1}{e^{Y}} d e^{U S}-e^{U S}\left(\frac{1}{e^{Y}}\right)^{2} d e^{Y}
$$

Inserting (9) and (IO) into (II) under the simplifying assumption of marginal private portfolio composition being close to average private portfolio composition yields: ${ }^{12}$

$$
d e^{\text {cross }}=-\frac{e^{U S}}{e^{Y} S^{U S}} d S^{U S}+\frac{e^{U S}}{e^{Y} S^{Y}} d S^{Y}
$$

For changes in the exchange rates as a result of an increase of the supply of dollars, yen, and euros, we thus get:

$$
\begin{aligned}
& \left.\frac{d e^{U S}}{d S^{U S}}\right|_{d S^{E U}=d S^{Y}=0}=-\frac{e^{U S}}{S^{U S}} \quad<0 \\
& \left.\frac{d e^{Y}}{d S^{Y}}\right|_{d S^{E U}=d S^{U S}=0}=-\frac{e^{Y}}{S^{Y}} \quad<0 \\
& \left.\frac{d e^{U S}}{d S^{E U}}\right|_{d S^{U S}=d S^{Y}=0}=-\frac{A_{W}^{U S}}{A_{W}^{E U} S^{U S}} \quad>0 \\
& \left.\frac{d e^{Y}}{d S^{E U}}\right|_{d S^{U S}=d S^{Y}=0}=-\frac{A_{W}^{Y}}{A_{W}^{E U} S^{Y}} \quad>0 \\
& \left.\frac{d e^{\text {cross }}}{d S^{U S}}\right|_{d S^{U S}=d S^{Y}=0}=-\frac{e^{U S}}{e^{Y} S^{U S}} \quad<0 \\
& \left.\frac{d e^{\text {cross }}}{d S^{Y}}\right|_{d S^{U S}=d S^{Y}=0}=\frac{e^{U S}}{e^{Y} S^{Y}} \quad>0 \\
& \left.\frac{d e^{Y}}{d S^{U S}}\right|_{d S^{E U}=d S^{Y}=0}=\left.\frac{d e^{U S}}{d S^{Y}}\right|_{d S^{E U}=d S^{U S}=0}=\left.\frac{d e^{\text {cross }}}{d S^{E U}}\right|_{d S^{Y}=d S^{U S}=0}=0
\end{aligned}
$$

II For computational details, see the appendix.

I2 For computational details, please refer to the appendix. 
An increase of the supply of U.S.-dollars thus leads to a depreciation of the dollar towards the euro and the yen, while leaving the exchange rate between euro and yen unchanged. Similarly, an increase in the supply of euro assets leads to a depreciation of the euro against all currencies, an increase in the supply of yen assets to a depreciation of the yen. An increase in the number of yen assets leaves the dollar/euro exchange rate unaltered as an increase in euro assets leaves the yen/dollar exchange rate unchanged.

\subsection{Graphical Representation}

The equilibrium in the asset markets and the change in the exchange rates can also be represented in graphical terms. ${ }^{13}$ Equilibrium in each of the three asset markets (for euro, dollar and yen) is depicted by a graph in a $e^{Y}-e^{U S}$ space as in figure $\mathrm{I}$. At the intersection of all three lines in point $A$, all three markets are in equilibrium and we can deduct the equilibrium exchange rates. While the bilateral exchange rates against the euro can be read on the horizontal and vertical axis, the exchange rate between dollar and yen can be deduced by drawing a line from the origin of the coordinate system $A$ through the equilibrium point in all three asset markets. As $e^{\text {cross }}$ is the simple ratio between the two bilateral exchange rates with the euro, the slope of this curve is $\frac{1}{e^{\operatorname{mas}}}$.

Figure I: Basic Graphical Representation

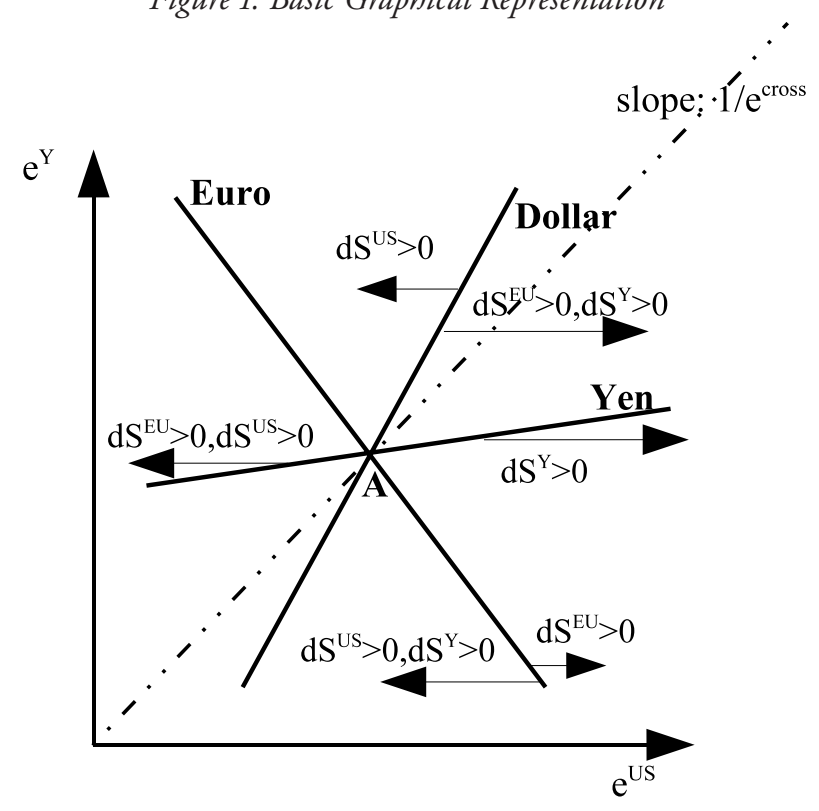

I3 For a similar graphical representation of the simple Branson-model, see Gärtner (1997: I48ff). 
To get the slopes of each of the three asset market curves, the implicit function theorem is used. ${ }^{\mathrm{I}}$ We thus get:

$$
\begin{array}{cc}
\left.\frac{d e^{Y}}{d e^{U S}}\right|_{\text {dollar }}=\frac{S^{U S}\left(1-A_{W}^{U S}\right)}{S^{Y} A_{W}^{U S}}>0 & >0 \\
\left.\frac{d e^{Y}}{d e^{U S}}\right|_{\text {yen }}=\frac{S^{U S} A_{W}^{Y}}{S^{Y}\left(1-A_{W}^{Y}\right)} & >0 \\
\left.\frac{d e^{Y}}{d e^{U S}}\right|_{\text {euro }}=-\frac{S^{Y}}{S^{U S}} & <0
\end{array}
$$

As is shown in the appendix, (2I) is smaller than (2O). Thus, the slope of the yen and dollar curves are positive, while the dollar curve is steeper. The slope of the euro curve is negative.

Taking a look at the basic equations (I) to (3), we can conclude how the curves would shift should the supply of any asset change. Let us start with the curve depicting equilibrium in the market for dollar assets: If the supply of dollar assets increases, also overall private wealth $W$ increases, thus pushing demand for dollar assets up as we see in (I). However, as the additional wealth is distributed between all three assets, supply increases by more than demand. As a result, we get an excess supply in the market for dollar assets. Equilibrium will only be reached if the exchange rate falls, thus lowering both supply and demand in euro terms again. Thus, such an increase in $S^{U S}$ leads to a shift of the dollar curve to the left. After an increase in the supply of euro or yen assets, on the other hand, only the demand for dollar assets increases due to the wealth effect while the right hand side of equation (I) remains unchanged. In these cases, a new equilibrium in the market for dollar assets can only be found if the dollar appreciates (represented by a shift of the dollar curve to the right).

Similar arguments can be made for the other two curves: After an increase of the supply of yen assets, there is excess supply in the yen asset market which can be cured by an appreciation of the euro/dollar exchange rate (which increases nominal wealth and thus the demand for yen assets). In this case, the yen-curve shifts to the right. An increase in the supply of dollar or euro assets, on the other hand, leads to excess demand in the yen market, making a fall in $e^{U S}$ necessary to reach a new equilibrium. In these cases, the yen curve shifts to the left.

For the euro asset market, an increase in the supply of euro assets $S^{E U}$ makes an appreciation of the dollar against the euro necessary in order to equilibrate supply and demand again. The euro curve shifts to the right. An increase in the supply of dollar or yen assets, on the other hand, makes an appreciation of the euro necessary, thus shifting the euro curve to the left.

I4 For computational details, please refer to the appendix. 


\section{The U.S. Current Account Deficit and Asian Dollar Purchases}

With these tools at hand, we can now start analysing what different policy actions or imbalances in the `Revived-Bretton-Woods` world will have for the exchange rate between the three currencies.

\section{I The U.S. Current Account Deficit}

Any current account deficit has to be financed by a change in the net wealth position of the country which runs the deficit. This can be modelled as the emission of securities in international asset markets. Thus, in this paper's model, a U.S. current account deficit leads to an increase in the supply of assets denominated in U.S. dollars in the world financial markets. In other words: The deficit in the current account is financed via the sale of U.S. bonds to investors outside the United States. Thus,

$$
d S^{U S}=C A
$$

with $C A$ denoting the U.S. current account deficit.

Figure 2: Basic Graphical Representation

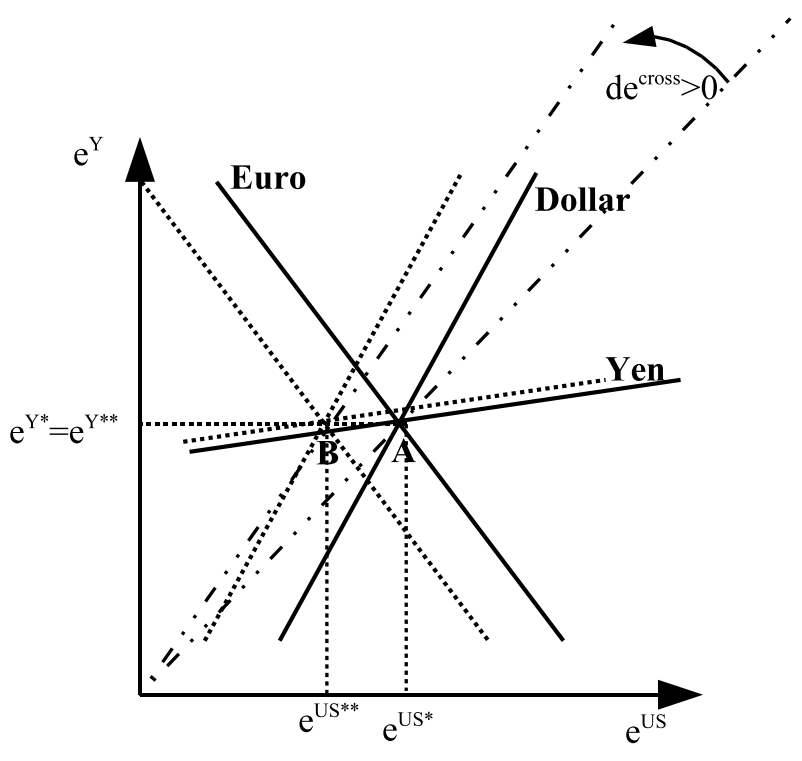

As we know from (9) and (Io), this increase in dollar assets leads to a depreciation of the dollar against both the euro and the yen. Alternatively, we can use the graphical representation to get to these results. An increase in $S^{U S}$ while letting the supply for the other two assets unchanged leads to a shift to the left of all three curves as shown in figure 2 . As can be 
seen by the shift from $e^{U S *}$ to $e^{U S * *}$, the dollar depreciates against the euro. The depreciation against the yen can be seen in the change in slope from the line from the origin of the coordinate system to the new equilibrium point $B$ compared to the old line going through point $A$. Thus, an American current account deficit in this model leads to a weaker dollar, just as is common sense in textbook economic models.

\subsection{Asian Central Bank's Purchase of Dollar Assets}

If Asian central banks try to limit the dollar's depreciation against their currencies, they will buy dollar assets against their own currency. This purchase can take the form of selling yendenominated securities from the central bank's portfolio. Alternatively, one can imagine that the central bank prints yen, but sterilizes the intervention in the domestic market (which would be in line with the assumption of fixed domestic interest rates). Thus, the supply of dollar assets decreases, while the supply of yen assets increases. As the value of dollar purchases needs to be paid in yen, for interventions

$$
d S^{U S}=-\frac{e^{Y}}{e^{U S}} d S^{Y}
$$

must hold. The effects of an intervention of the Asian central bank in order to weaken its own currency against the dollar are thus given by substituting (24) into (9) and (I2). The change of the euro/dollar and the yen/dollar exchange rates for an incremental sale of yen assets by the Asian central banks against dollar assets is consequently:

$$
\begin{aligned}
d e^{U S} & =-\frac{e^{U S}}{S^{U S}}\left(-\frac{e^{Y}}{e^{U S}} d S^{Y}\right)=\frac{e^{Y}}{S^{U S}} d S^{Y}>0 \\
d e^{\text {cross }}=\left(\frac{1}{S^{U S}}+\frac{e^{U S}}{e^{Y} S^{Y}}\right) d S^{Y} & >0
\end{aligned}
$$

The change in the euro/yen exchange rate is given by (I4). Thus, the intervention strengthens the dollar not only against the yen, but also against the euro, while it weakens the yen against both the euro and the dollar. The rationale behind this result running contrary to public perception is that the intervention decreases the supply of dollars in global financial markets. What is less surprising is the fact that the intervention also weakens the yen against the euro, as the global supply of yen assets is increased.

Again, this can also be shown in the graphical representation (figure 3): An increase in the supply of yen assets shifts the dollar curve to the right as does a decrease in the supply of dollar assets. A similar argument holds for the yen curve: An increase in the supply of yen assets shifts the curve to the right as does the decrease in the number of dollar assets available in international financial markets. Things are a little more complicated for the euro curve. Substituting (24) into the left hand side of (3), we see that a new equilibrium in the market for euro assets is reached without any change in the exchange rates. As the intervention does not change nominal wealth $W$ of the private sector, demand for euro assets does not change. Thus the euro curve remains stable and does not move. Consequently, a new 
equilibrium is reached in point $C$, with a depreciated yen vis-à-vis the euro and the dollar, and an appreciated dollar vis-à-vis euro and yen.

Figure 3: Asian Central Bank Buys Dollars Against Yen

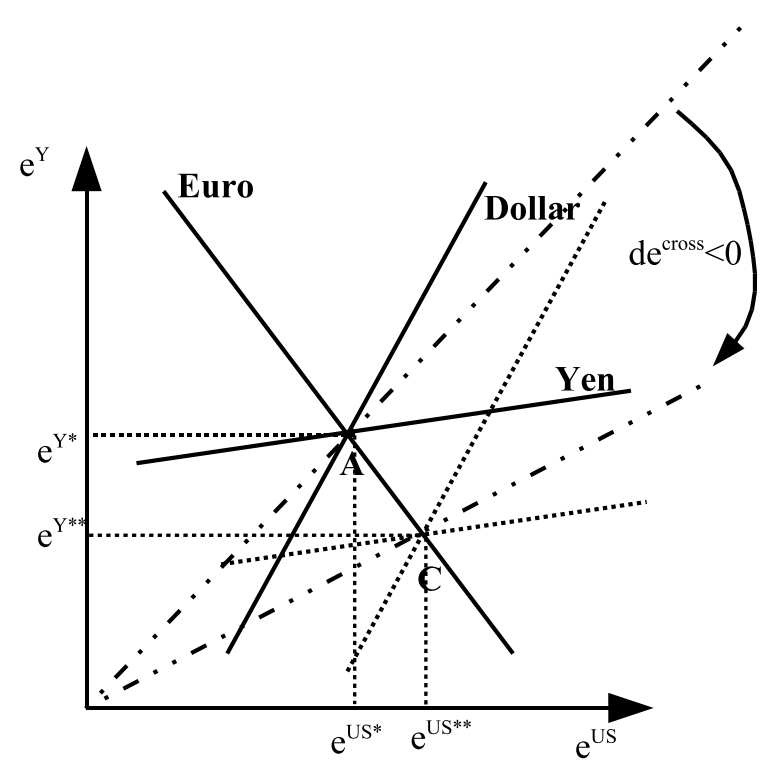

\section{Portfolio Diversification and the Currency Peg}

Lately, there has been a discussion whether Asian central banks might try to shift their portfolio allocation from a predominant dollar weight towards a more balanced portfolio. The notion behind this idea is that - as in the long run a dollar depreciation might be unavoidable - Asian central banks might want to protect their portfolios from large losses in value incured should the dollar fall. However, Dooley, Folkerts-Landau, and Garber (2004) have argued that such a policy would threaten the dollar peg of Asian currencies.

As will be shown in the following subsections, this need not necessarily be the case: The goal of foreign reserve diversification can be reached by two ways: The Asian central banks could sell some of their dollar holdings against the euro, thus lowering their absolute dollar holdings, or they could shift from intervening against the dollar towards intervening against the euro, thus increasing their euro holdings and lowering their relative dollar exposure. Only the first of these two options would mean a depreciation of the dollar against Asian currencies, the second would allow to keep the peg intact. 


\section{I Outright Dollar Sales Against the Euro}

The first way to reduce dollar exposure is an outright sale of dollar assets against euro assets. For these operations,

$$
e^{U S} d S^{U S}=-d S^{E U}
$$

must hold. Inserting (27) into (9), (IO) and (I2):

$$
\begin{aligned}
d e^{U S} & =-\left(\frac{e^{U S}}{S^{U S}}+\frac{A_{W}^{U S}}{A_{W}^{E U} S^{U S}}\right) e^{U S} d S^{U S} & <0 \\
d e^{Y} & =-\frac{A_{W}^{Y}}{A_{W}^{E U} S^{Y}} e^{U S} d S^{U S} & <0 \\
d e^{\text {cross }} & =-\frac{e^{U S}}{e^{Y} S^{U S}} d S^{U S} & <0
\end{aligned}
$$

Thus, an outright sale of dollar assets against euro assets strengthens the euro both against the yen and the dollar, while it weakens the dollar again both against the euro and the yen. From a European perspective, it is interesting to note that the euro appreciates more strongly against the dollar than against the yen. From an Asian perspective, it is crucial to note that the outright sale of dollars in world financial markets is not an option if Asian central banks wish to keep their own currency stable towards the euro. ${ }^{\text {I5 }}$

Figure 4: Diversification I: Asian Central Banks Sell Dollars Against Euro

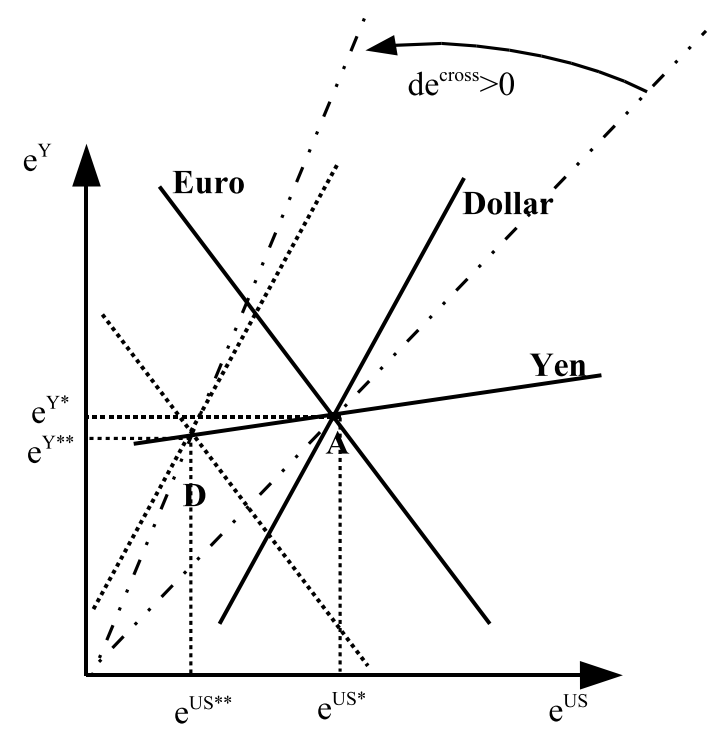

I5 This result is thus in line with Dooley et al. (2004). 
Figure 4 illustrates this argument: The Asian central bank's operation increases the global supply of dollar assets outside central banks while it decreases the global supply of euro assets. So, the supply of euro assets available for private investors is below the actual demand for these assets. Only a fall in the dollar exchange rate can dampen nominal wealth and thus the demand for euro assets enough to bring the market to a new equilibrium. The euro curve consequently shifts to the left. In the dollar market, in contrast, supply is now above private demand. Only a fall in the price of dollar assets - the exchange rate - can bring this market into equilibrium. Thus, the dollar curve also shifts to the left. On the yen market, neither demand nor supply has changed. As the central bank's operation is only a swap of private dollar against private euro assets, net private wealth $W$ remains unaltered, leaving also the demand for yen assets unchanged. Consequently, the yen curve does not shift at all.

In the new equiblibrium point $D$, we see that $e^{U S}$ and $e^{Y}$ have fallen, albeit $e^{U S}$ by a bigger margin than $e^{Y}$. In addition, as we see from the slope of the line from the origin of the coordinate system through $D$, the yen has appreciated against the dollar.

\subsection{Holding the Peg While Diversifying Exchange Rate Risk}

However, the outright sale of dollar against euro assets is not the only way Asian central banks can diversify their portfolio risk. As we know from portfolio theory, both the expected return and the risk of a portfolio depend on the relative shares of assets in that portfolio. Assuming that the risky Asian central bank portfolio only consists of dollar assets $R^{U S}$ and euro assets $R^{E U}{ }^{16}$ for total reserves of the central bank written in yen we get:

$$
R=e^{\text {cross }} R^{U S}+\frac{1}{e^{Y}} R^{E U}
$$

Shares of dollar assets $\alpha^{U S}$ and euro assets $\alpha^{E U}$ in this portfolio would thus be: ${ }^{17}$

$$
\begin{aligned}
\alpha^{U S} & =\frac{e^{\text {cross }} R^{U S}}{R} \\
\alpha^{E U} & =\frac{R^{E U}}{e^{Y} R}
\end{aligned}
$$

From portfolio theory we know that the return on this portfolio $\mathrm{m}$ is the weighted average of the returns on dollar assets $\mu^{U S}$ and euro assets $\mu^{E U}$ :

$$
\mu=\alpha^{U S} \mu^{U S}+\alpha^{E U} \mu^{E U}
$$

while the variance of this portfolio, var, is given by the portfolio shares, the variance of dollar assets var ${ }^{U S}$, the variance of euro assets $\operatorname{var}^{E U}$ and the covariance between dollar and euro assets $\operatorname{cov}^{U S E U}$ :

$$
\text { var }=\left(\alpha^{U S}\right)^{2} \operatorname{var}^{U S}+2 \alpha^{U S} \alpha^{E U} \operatorname{cov}^{U S E U}+\left(\alpha^{E U}\right)^{2} \operatorname{var}^{E U}
$$

I6 Domestic assets can be assumed to be free of exchange rate risk.

I7 For a quick overview of portfolio theory, see Elton et al. (2003). 
Assuming that any appreciation of the Asian currency could partly be bolstered by foreign exchange interventions so that the Asian currency appreciates less against the dollar than the euro does, $\mathrm{cov}^{U S / E U}$ would even be negative. Thus, by increasing the share of euro assets regardless of the absolute size of the portfolio significantly decreases the risk of losses due to a further dollar depreciation.

Such an increase of the share of euro assets could be brought about by a foreign exchange market intervention against the euro. Moreover, this purchase would fulfill a double purpose: It would also weaken the yen against the dollar. As we know from (II), a purchase of dollars is not necessary to bring about a depreciation of the yen against the dollar. A sale of yen against euro would also do the trick, even though the interventions would need to be bigger than in the case where a sale of yen would come with a purchase of dollars.

As the value of assets purchased and sold has to be equal in foreign exchange interventions,

$$
d R^{E U}=-d S^{E U}=\frac{1}{e^{Y}} d S^{Y}
$$

must hold. Inserting (36) into (9), (IO) and (I2) yields for exchange rate reactions:

$$
\begin{array}{rlr}
d e^{U S} & =-\frac{A_{W}^{U S}}{e^{Y} A_{W}^{E U} S^{U S}} d S^{Y} & <0 \\
d e^{Y} & =-\left(\frac{e^{Y}}{S^{Y}}+\frac{A_{W}^{Y}}{e^{Y} A_{W}^{E U} S^{Y}}\right) d S^{Y} & <0 \\
d e^{\text {cross }} & =\frac{e^{U S}}{e^{Y} S^{Y}} d S^{Y} & >0
\end{array}
$$

Thus, the euro appreciates against both dollar and yen, while the yen depreciates against dollar and euro.

The policy of holding the exchange rate between the Asian currencies and the dollar constant while reducing relative central bank portfolio exposure by intervening against the euro is illustrated again in figure 5. This figure builds on figure $\mathrm{I}$, in which an increase in dollar assets as the consequence of the U.S. current account deficit has led to a depreciation of the dollar against euro and yen. The new equibilibrium point now is point $B$. Starting from this point, the Asian central bank tries to reach again the same bilateral exchange rate between yen and dollar which had been in effect before the initial depreciation of the dollar. To this end, the central bank buys euro and sells yen in the foreign exchange market. In the market for euro assets, this leads to excess demand which can only be cured by a depreciation of the dollar against the euro, thus dampening nominal wealth $W$ and depressing demand for euro assets again. Consequently, the euro curve shifts to the left. In the yen market, there is now excess supply in yen assets. An increase in $e^{U S}$ can eliminate this excess supply as this would increase nominal wealth and thus the demand for yen assets. Consequently, the yen curve shifts to the right. In the new equilibrium point $E$, both dollar and yen have depreciated significantly against the euro while the cross exchange rate is at the 
initial level. At the same time, euro holdings of the Asian central bank have increased, thus lowering the risk of wealth loss should the dollar depreciate.

\section{Figure s: Asian Central Bank Intervenes Against Euro}

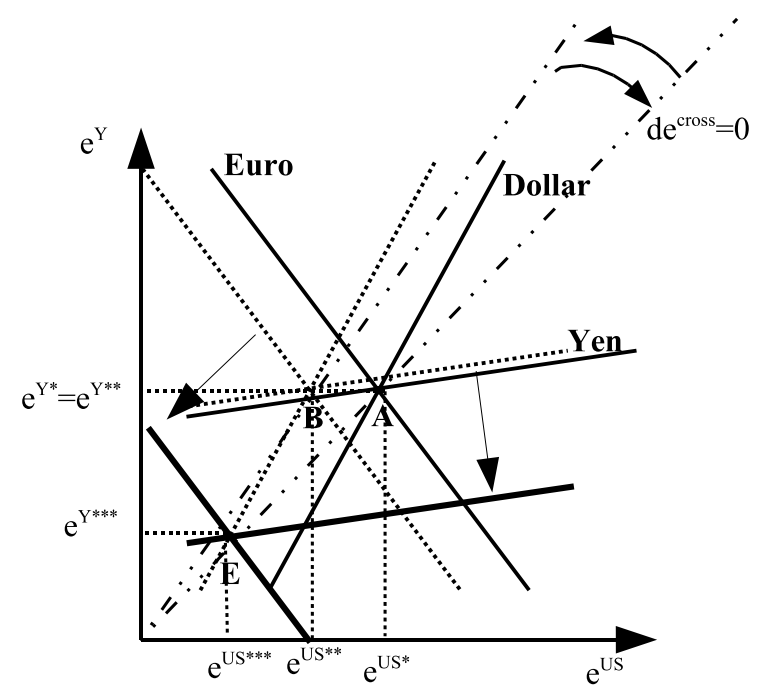

From a portfolio perspective and given that Asian central banks hold a large share of their assets in dollar ${ }^{18}$, the optimal strategy for Asian central banks would thus be to first shift their currency intervention into euros and only later start to sell dollar against euro. Should the Asian central banks try to diversify by outright selling their dollar against euro assets, they would risk a large loss in value of their portfolio. Should they, however, first shift their foreign exchange interventions towards euro and start selling dollar only after they have significantly increased their euro holdings, they could have altered portfolio shares $\alpha^{U S}$ an $\alpha^{E U}$ in a way that the impact of the depreciation of the dollar on their portfolio could be compensated by the impact of the appreciation of the euro resulting from outright dollar sales. This would mean that Europe would have to count on a further large depreciation of both yen and dollar before a 'Bretton Woods 2 « system might finally unravel. Of course, for Asia, such a strategy would mean a continuation of the foreign exchange interventions for quite a while which might put into jeopardy other goals as domestic monetary stability. However, as this paper's scope is only the short-run effect of interventions on the exchange rates, these consequences will not be elaborated on here. 


\section{Conclusion}

This paper has shown that the revived Bretton Woods system $<$ - as economists call the policy of some Asian countries of pegging their currency against the dollar by buying dollar assets on a large scale - has a strong influence on the bilateral euro exchange rates both with the United States and Asia. Contrary to common belief, but in line with Blanchard et al. (2005), the Asian peg by itself and the resulting dollar purchases strengthen the dollar against the euro. However, as soon as Asian central banks diversify their dollar holdings into euro, the dollar would plunge. From the European perspective of trying to protect the competitiveness of European industries in the world market, an even more threatening scenario would be that Asian central banks could move from buying dollars in order to keep their peg intact towards buying euro against newly printed yen or yuan. While such a strategy would enable the Asian countries to keep their peg against the dollar intact at the same time as they diversify their foreign exchange portfolios, it would mean that the euro strongly appreciates against both dollar and yen.

\section{A Mathematical Appendix}

\section{A.I Solving the System}

To get $d e^{U S}$ and $d e^{Y}$, we need to solve the system (6) to (8). As we have two endogenous variables only, and Walras' law tells us that the third market will be in equilibrium when two of the three asset markets are in equilibrium ${ }^{19}$, we can drop equation (8). Rearranging (6) and (7) and writing in matrix notation $A x=d$ gives us:

$$
\begin{aligned}
& \left(\begin{array}{cc}
\left(A_{W}^{U S}-1\right) S^{U S} & A_{W}^{U S} S^{Y} \\
A_{W}^{Y} S^{U S} & \left(A_{W}^{Y}-1\right) S^{Y}
\end{array}\right)\left(\begin{array}{c}
d e^{U S} \\
d e^{Y}
\end{array}\right) \\
& =\left(\begin{array}{c}
\left(1-A_{W}^{U S}\right) e^{U S} d S^{U S}-A_{W}^{U S} e^{Y} d S^{Y}-A_{W}^{U S} d S^{E U} \\
-A_{W}^{Y} e^{U S} d S^{U S}+\left(1-A_{W}^{Y}\right) e^{Y} d S^{Y}-A_{W}^{Y} d S^{E U}
\end{array}\right)
\end{aligned}
$$

To apply Cramer's rule, we first need to compute the determinant of the matrix $A$ :

$$
\begin{aligned}
|A| & =\left(A_{W}^{U S}-1\right) S^{U S}\left(A_{W}^{Y}-1\right) S^{Y}-A_{W}^{Y} S^{U S} A_{W}^{U S} S^{Y} \\
& =\left(1-A_{W}^{U S}-A_{W}^{Y}\right) S^{U S} S^{Y}
\end{aligned}
$$

As all wealth has to be invested, we get from (4):

$$
A_{W}^{U S}+A_{W}^{E U}+A_{W}^{Y}=1
$$

Using (43), we get from (42): 


$$
|A|=A_{W}^{E U} S^{U S} S^{Y}
$$

Applying Cramer's rule to the system yields for $d e^{U S}$ :

$$
\begin{aligned}
d e^{U S} & =\frac{1}{|A|}\left[A_{W}^{Y} S^{Y}-A_{W}^{Y} A_{W}^{U S} S^{Y}-S^{Y}+A_{W}^{U S} S^{Y}+A_{W}^{U S} A_{W}^{Y} S^{Y}\right] e^{U S} d S^{U S} \\
& +\frac{1}{|A|}\left[-A_{W}^{Y} A_{W}^{U S} S^{Y}+A_{W}^{U S} S^{Y}-A_{W}^{U S} S^{Y}+A_{W}^{U S} A_{W}^{Y} S^{Y}\right] e^{Y} d S^{Y} \\
& +\frac{1}{|A|}\left[-A_{W}^{Y} A_{W}^{U S} S^{Y}+A_{W}^{U S} S^{Y}+A_{W}^{Y} A_{W}^{U S} S^{Y}\right] d S^{E U} \\
& =\frac{1}{|A|}\left(A_{W}^{Y}+A_{W}^{U S}-1\right) S^{Y} e^{U S} d S^{U S}+\frac{1}{|A|}\left(S^{Y} A_{W}^{U S}\right) d S^{E U}
\end{aligned}
$$

With (43), (46) becomes:

$$
\begin{aligned}
d e^{U S} & =\frac{1}{|A|}\left[-A_{W}^{E U} S^{Y} e^{U S} d S^{U S}+A_{W}^{U S} S^{Y} d S^{E U}\right] \\
& =-\frac{e^{U S}}{S^{U S}} d S^{U S}+\frac{A_{W}^{U S}}{A_{W}^{E U} S^{U S}} d S^{E U}
\end{aligned}
$$

Analogously, we get for $d e^{Y}$ :

$$
\begin{aligned}
d e^{Y}= & \frac{1}{|A|}\left[A_{W}^{U S} S^{U S}-A_{W}^{U S} A_{W}^{Y} S^{U S}-S^{U S}+A_{W}^{Y} S^{U S}+A_{W}^{Y} A_{W}^{U S} S^{U S}\right] e^{Y} d S^{Y} \\
& +\frac{1}{|A|}\left[-A_{W}^{U S} A_{W}^{Y} S^{U S}+A_{W}^{Y} S^{U S}-A_{W}^{Y} S^{U S}+A_{W}^{Y} A_{W}^{U S} S^{U S}\right] e^{U S} d S^{U S} \\
& +\frac{1}{|A|}\left[-A_{W}^{U S} A_{W}^{Y} S^{U S}+A_{W}^{Y} S^{U S}+A_{W}^{U S} A_{W}^{Y} S^{U S}\right] d S^{E U} \\
& =\frac{1}{|A|}\left(A_{W}^{U S}+A_{W}^{Y}-1\right) S^{U S} e^{Y} d S^{Y}+\frac{1}{|A|}\left(S^{U S} A_{W}^{Y}\right) d S^{E U}
\end{aligned}
$$

With (43), (50) becomes:

$$
\begin{aligned}
d e^{Y} & =\frac{1}{|A|}\left[-A_{W}^{E U} S^{U S} e^{Y} d S^{Y}+A_{W}^{Y} S^{U S} d S^{E U}\right] \\
& =-\frac{e^{Y}}{S^{Y}} d S^{Y}+\frac{A_{W}^{Y}}{A_{W}^{E U} S^{Y}} d S^{E U}
\end{aligned}
$$

From (48) and (52), we can easily deduce (I3) to (I6). 
Totally differentiating (5) yields

$$
d e^{\text {cross }}=\frac{1}{e^{Y}} d e^{U S}-\frac{e^{U S}}{\left(e^{Y}\right)^{2}} d e^{Y}
$$

Inserting (9) and (Io) gives us

$$
\begin{aligned}
d e^{\text {cross }} & =-\frac{e^{U S}}{e^{Y} S^{U S}} d S^{U S}+\frac{A_{W}^{U S}}{e^{Y} A_{W}^{E U} S^{U S}} d S^{E U} \\
& +\frac{e^{U S}}{e^{Y} S^{Y}} d S^{Y}-\frac{e^{U S} A_{W}^{Y}}{\left(e^{Y}\right)^{2} A_{W}^{E U} S^{Y}} d S^{E U} \\
& =-\frac{e^{U S}}{e^{Y} S^{U S}} d S^{U S}+\frac{e^{U S}}{e^{Y} S^{Y}} d S+\frac{e^{Y} S^{Y} A_{W}^{U S}-e^{U S} S^{U S} A_{W}^{Y}}{\left(e^{Y}\right)^{2} A_{W}^{E U} S^{Y} S^{U S}} d S^{E U}
\end{aligned}
$$

Rearranging the numerator of the last term in (55) gives as a condition for which this term is 0 :

$$
\begin{aligned}
e^{Y} S^{Y} A_{W}^{U S}-e^{U S} S^{U S} A_{W}^{Y} & =0 \\
\Leftrightarrow \quad \frac{A_{W}^{Y}}{A_{W}^{U S}} & =\frac{e^{Y} S^{Y}}{e^{U S} S^{U S}}
\end{aligned}
$$

As $e^{Y} S^{Y}$ denotes the euro value of yen assets and $e^{U S} S^{U S}$ the value of dollar assets held in private portfolios, this term can be interpreted as follows: If actual porfolio composition equals marginal portfolio composition should aggregate nominal wealth $W$ increase, this term is 0 . For simplicity, we assume for the rest of the paper that the average portfolio composition equals the marginal portfolio composition ${ }^{20}$ and thus the last term in (55) to be 0 .

\section{A.2 Slopes For the Graphical Representation}

For getting the slopes of the three curves depicting equilibria in the three asset markets, we use the implicit function theorem. To this end, we first rearrange (4) into (I) to (3) and rearrange:

$$
\begin{array}{r}
A^{U S}\left(i^{U S}, i^{Y}, i^{E U}, e^{U S} S^{U S}+e^{Y} S^{Y}+S^{E U}\right)-e^{U S} S^{U S}=0 \\
A^{Y}\left(i^{U S}, i^{Y}, i^{E U}, e^{U S} S^{U S}+e^{Y} S^{Y}+S^{E U}\right)-e^{Y} S^{Y}=0 \equiv \Omega \\
A^{E U}\left(i^{U S}, i^{Y}, i^{E U}, e^{U S} S^{U S}+e^{Y} S^{Y}+S^{E U}\right)-S^{E U}=0 \equiv \Psi
\end{array}
$$

Now we apply the implicit function theorem to get the slopes in the $e^{U S}-e^{U S}$ space:

20 This implies that neither of the assets is a superior or inferior good in the eyes of the investors. 


$$
\begin{aligned}
& \left.\frac{d e^{Y}}{d e^{U S}}\right|_{\text {dollar }}=\frac{-\Gamma_{e^{U S}}}{\Gamma_{e^{Y}}}=\frac{S^{U S}\left(1-A_{W}^{U S}\right)}{S^{Y} A_{W}^{U S}}>0 \\
& \left.\frac{d e^{Y}}{d e^{U S}}\right|_{\text {yen }}=\frac{-\Omega_{e^{U S}}}{\Omega_{e^{Y}}}=\frac{S^{U S} A_{W}^{Y}}{S^{Y}\left(1-A_{W}^{Y}\right)}>0 \\
& \left.\frac{d e^{Y}}{d e^{U S}}\right|_{\text {euro }}=\frac{-\Psi_{e^{U S}}}{\Psi_{e^{Y}}}=\frac{-S^{U S} A_{W}^{E U}}{S^{Y} A_{W}^{E U}}=-\frac{S^{U S}}{S^{Y}}<0
\end{aligned}
$$

Using (43), equation (62) can be rewritten as $\frac{S^{U S}\left(1-A_{W}^{U S}-A_{W}^{E U}\right)}{S^{Y}\left(A_{W}^{U S}+A_{W}^{U E}\right)}$. Now we see that the numerator of this term is smaller than the numerator in (6I), while the denominator is larger. Consequently, the slope of the yen curve in the graphical representation is smaller than that of the dollar curve.

\section{References}

Blanchard, O.F., Giavazzi, F.S. (2005): The U.S. current account and the dollar, NBER Working Paper, No. III37.

Branson, W.H. (1979): Exchange rate dynamics and monetary policy, in: Lindbeck, A. (ed.), Inflation and unemployment in open economies, Amsterdam, I89-224.

Branson, W.H., Henderson, D.W. (1985): The specification and influence of asset marktes, in: Jones, R.W., Kenen, P.B. (eds.), Handbook of International Economics II, Amsterdam, chap. I5.

Dominguez, K.M., Frankel, J.A. (1993): Does foreign-exchange intervention matter? The portfolio effect, American Economic Review, 83, 1356-1369.

Dooley, M., Folkerts-Landau, D., Garber, P. (2003): An essay on the revived Bretton Woods System, NBER Working Paper, No. 997I.

Dooley, M., Folkerts-Landau D., Garber, P. (2004): The revived Bretton Woods System: The effects of periphery intervention and reserve management on interest rates \& ex-change rates in center countries, NBER Working Paper, No. I0332.

Eichengreen, B. (2004): Global imbalances and the lessons of Bretton Woods, NBER Working Paper, No. 10497.

Elton, E.J., Gruber, M.J., Brown, S.J.,Goetzmann, W.N. (2003): Modern portfolio theory and investment analysis, Hoboken, NJ: John Wiley and Sons.

Gandolfo, G. (2002): International finance and open-economy macro-economics, Berlin: Springer.

Gärtner, M. (1997): Makroökonomik flexibler und fester Wechselkurse, Berlin: Springer.

Roubini, N., Setser, B. (2005): Will the Bretton Woods 2 regime unravel soon? The risk of a hard landing in 2005-2006, unpublished typescript.

Sarno, L., Taylor, M.P. (200I): Official intervention in the foreign exchange market: Is it effective and, if so, how does it work?, Journal of Economic Literature, 34, 839-868. 
